\title{
Assessing Acceptance of Assistive Social Agent Technology by Older Adults: the Almere Model
}

\author{
Marcel Heerink • Ben Kröse • Vanessa Evers • \\ Bob Wielinga
}

Accepted: 21 July 2010 / Published online: 4 September 2010

(c) The Author(s) 2010. This article is published with open access at Springerlink.com

\begin{abstract}
This paper proposes a model of technology acceptance that is specifically developed to test the acceptance of assistive social agents by elderly users. The research in this paper develops and tests an adaptation and theoretical extension of the Unified Theory of Acceptance and Use of Technology (UTAUT) by explaining intent to use not only in terms of variables related to functional evaluation like perceived usefulness and perceived ease of use, but also variables that relate to social interaction. The new model was tested using controlled experiment and longitudinal data collected regarding three different social agents at elderly care facilities and at the homes of older adults. The model was strongly supported accounting for $59-79 \%$ of the variance in usage intentions and $49-59 \%$ of the variance in actual use. These findings contribute to our understanding of how elderly users accept assistive social agents.
\end{abstract}

Keywords Technology acceptance - Assistive technology · Elderly users $\cdot$ Social robots $\cdot$ Embodied agents

\author{
M. Heerink $(\varangle)$ \\ Amsterdam University of Applied Sciences, P.J. Oudweg 25, \\ Almere, The Netherlands \\ e-mail: m.heerink@windesheimflevoland.nl \\ B. Kröse $\cdot$ V. Evers $\cdot$ B. Wielinga \\ University of Amsterdam, Science Park 904, Amsterdam, \\ The Netherlands \\ B. Kröse \\ e-mail: b.j.a.krose@uva.nl \\ V. Evers \\ e-mail: v.evers@uva.nl \\ B. Wielinga \\ e-mail: b.j.wielinga@uva.nl
}

\section{Introduction}

The expected growth in the elderly population and projected short- and long term labor shortages in healthcare [1] have inspired researchers to explore the applicability of intelligent systems for eldercare. These systems are expected to enable elderly people to live independently and make more efficient use of human care services [2]. However, previous research has shown that systems and applications that are developed for elderly users are often discarded due to factors that are specific for this user group, like social pressures (such as stigmatization) or lack of adaptiveness to changes in the physical and cognitive condition [3, 4]. In order to fully understand the process of acceptance of intelligent systems for eldercare, it will be important to identify these factors.

Among the efforts to develop intelligent systems for eldercare are projects in which robots and screen agents are developed as an integrated part of intelligent homes or as personal assistive devices [5]. They are designed to interact socially with users to increase acceptance and to ease communication and coordination [6, 7]. However, if autonomous social agents are going to stay at care facilities and homes of elderly people, we need to understand the motivations of elderly and the process by which they come to accept or reject this technology. How will elderly people respond to these agents? Will differences in the agent's social abilities cause a difference in attitudes toward the agent? Understanding these questions, would enable us to improve the design and presentation of social agents for elderly users.

A methodology that has been explicitly developed to research acceptance is technology acceptance modeling (TAM) [8]. It is used to map influences on users' intention to use the technology and the actual use of it. It can predict how well a system will be accepted by a certain user group and explain differences between individuals or sub 
groups. However, traditional technology acceptance models do not take into account social aspects of interaction with embodied agents such as robots or on-screen characters, nor are these models developed with elderly users in mind. In this paper we describe the development of a model for the acceptance of assistive social agents for elderly users. Our aim is to develop a model that (1) is able to explain acceptance under a wide variety of experimental conditions, (2) shows robustness during quantitative analysis and (3) aims to identify the main influences on acceptance of assistive social robots by elderly users.

In the remainder of this paper we will first discuss related work on the use of robots and screen agents in eldercare and existing models of technology acceptance. Subsequently, a new theoretical model of assistive social agent acceptance is developed and validated in four controlled user experiments with different robots and screen agents and with elderly users as participants. After reporting the findings from these experiments, we will present the improved and final model.

\section{Related work}

\subsection{Assistive Social Agents in Eldercare}

In today's world many elderly people require care from specialized caregivers. However, the availability of caregivers is insufficient to keep up with the rise in demand for such services. An important challenge for system designers is to use healthcare professional's time in the most efficient way and develop systems that can assist older adults. Some example technologies that are being developed for physical support are walking aids, intelligent wheelchairs, exoskeletons and robotic butlers [9-11]. Sensor monitoring systems and reminder devices are developed to offer cognitive assistance [12] and for social support there are solutions such as communication devices and robotic pets [13, 14]. Projects that address all three support categories are frequently envisioned as intelligent homes that provide a monitoring environment through intelligent sensor networks, control of household devices, medication reminders, as well as robotic assistive devices. These robots are developed to assist with walking, getting out of bed, bathing, toileting and household maintenance [15-17]. In certain cases, these robots are designed to interact socially with their users in order to invoke human social behaviors and ease communication $[15,17-19]$. We identify those as assistive social robots separately from other assistive technology that does not interact socially with its users. This is not to say that people will not interact with other assistive technology as if it were a social actor. This effect found by Reeves and Nass [20] is likely for all computer technology. However, in this research we will

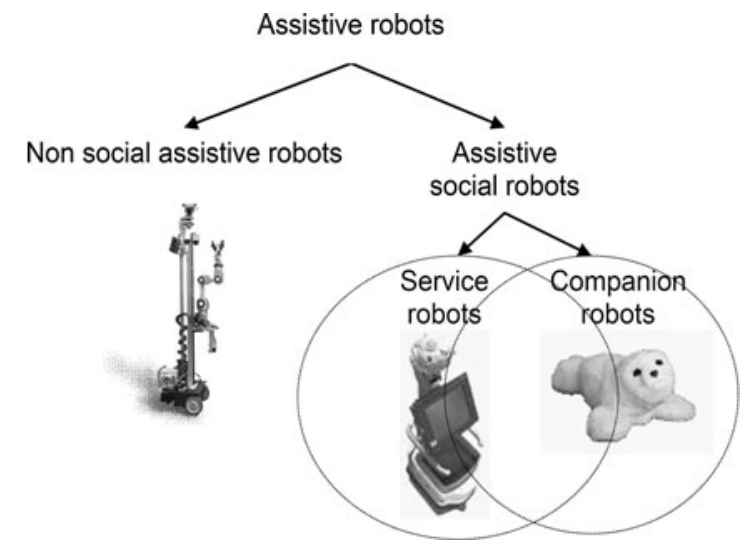

Fig. 1 Categorization of robots in eldercare

focus on technology that is specifically designed to interact socially with elderly users.

Research on assistive social robots for eldercare can be generally found in two areas (see Fig. 1). The first concerns social support and involves companion type robots used for social companionship or for robot assisted therapy. The other relates to robots that offer physical and cognitive assistance. These are socially interactive robots that carry out service tasks. They guide or carry persons, offer butlerlike services or function as an interface to smart home devices.

An example of a companion type social robot is the seal shaped robot Paro [19]. Shibata et al's findings suggest that Paro can have the same beneficial effect on elderly users as real pets, improving their health and sense of wellbeing. Another example of a companion type robot is the Huggable [21], developed to measure the way it is touched, intended to be connected to a separate computer at the nurse's station to promote the overall health and wellbeing of the user.

An example of a service type social robot is 'nursebot' Pearl, which is developed specifically for human-robot interaction research in elderly care. Pearl can provide assistance to elderly users [18], for example by guiding them to a destination or providing information. A robot with advanced assistive functionalities for eldercare is the German Care-o-bot. It is intended to provide assistance such as walking assistance and butler services $[8,22]$. Other projects focus on assistive environments rather then the development of a dedicated robot. An example of this is the RoboCare project [17], featuring an intelligent home of which a robot is an integrated part.

An example of research involving screen agents for elderly users is reported by Bickmore et al. [23]. It concerns the evaluation of elderly users' responses to relational agent Laura, which functioned as a health advisor for older adults. This agent's interaction consisted entirely of relationshipbuilding dialogue including social dialogue, meta-relational 
dialogue, empathy exchanges, humor, and reciprocal selfdisclosure exchanges. The studies' findings indicate that the agent was accepted by the participants as a conversational partner on health and health behavior. It was seen as trustworthy and friendly and found to be a good health advisor. Other research with this agent by Bickmore and Schulman [24] focused on long term relationships. It was found that even though subjects conducted an extended dialogue with the agent, they apparently failed to develop a strong social bond. These studies carefully suggest that in order to achieve acceptance of a social agent, social behavior is important but establishing a long term social relationship may not be needed.

Studies which compared robots and screen agents show that people respond to them in a similar way although a robotic agent is trusted slightly more than a screen agent. The actual embodiment of the robot was found more appealing than a screen agents virtual embodiment $[25,26]$.

Even if this review offers a limited sample of the studies available on the interaction of older adults with social robots, the work on elderly users' responses to robot care suggests that a robot's social behaviors are important. When a robot or screen agent is a character with its own social presence and sociability, users' expectations are destined to influence use and acceptance of the robot.

We argue that research on robot and agent acceptance can be subdivided into two areas: acceptance of the robot in terms of usefulness and ease of use (functional acceptance) and acceptance of the robot as a conversational partner with which a human or pet like relationship is possible (social acceptance). The experiments with Paro were more focused on social acceptance while the experiments with Pearl focused more on the acceptance of the robot regarding its functionalities. A complete methodology thus, should incorporate both these aspects of acceptance.

\subsection{UTAUT and the Acceptance of Social Agents}

The original Technology Acceptance Model (TAM) developed by Davis [6] (see Fig. 2), was based on the Theory of Reasoned Action (TRA) by Fishbein and Ajzen [27, 28]. In TAM, perceived ease of using the technology and the perceived usefulness of the technology are the main factors that influence the user's intent to use the system, which in turn is the main predictor of actual use of the system.

TAM, which defines acceptance as actual use, has been applied to evaluate the acceptance of many different types of technology and the model has been adapted and expanded upon in later research. Venkatesh et al. [29] offered an overview of these later technology acceptance models and incorporated the most reliable constructs into the Unified Theory of Acceptance and Use of Technology (UTAUT) model (Fig. 3). In UTAUT, perceived usefulness of the technology encompasses a broader definition and is renamed to

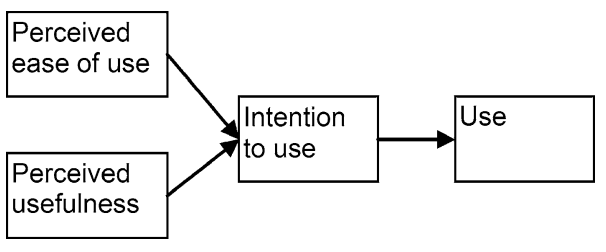

Fig. 2 Basic TAM assumptions

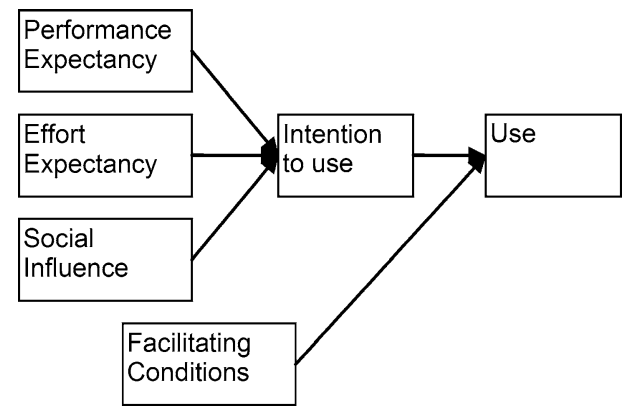

Fig. 3 UTAUT model: direct influences

Performance Expectancy (the expectations the user has of the performance of the system). Perceived ease of use is also more broadly defined and is termed Effort Expectancy (the expectations the user has of the effort that is needed to use the system). Other factors that have been incorporated are Social Influence and Facilitating Conditions. Self Efficacy, Attitude and Anxiety were not found to have a direct effect on Intention to Use (the effect was captured by effort and performance expectancy). Gender, Age, Experience and Voluntariness of use were found to be the main moderating influences. The model has been applied by De Ruyter et al. [30] to investigate the acceptance of a social robot (the iCat). These studies found that participants judged an extravert robot (more expressive in voice and facial expressions) to be more socially intelligent and they were more likely to accept the expressive robot compared with the robot in an introvert condition. The UTAUT model seems a sound basis to start exploring factors that determine elderly users acceptance of social robots. This is due to its extensive validation and the potential applicability of the model to human-robot interaction as indicated by de Ruyter et al.

\section{Model Development: Constructs and Hypothesized Construct Interrelations}

\subsection{Adopted Constructs}

The UTAUT questionnaire is presented with the notion that it will need to be adapted to the specific technology it evaluates [39]. Questionnaire items were therefore adapted in our research to fit the context of assistive robot and screen agent technology and address elderly users in a (care) home rather 
Table 1 Overview of constructs

\begin{tabular}{|c|c|c|}
\hline Code & Construct & Definition \\
\hline ANX & Anxiety & $\begin{array}{l}\text { Evoking anxious or emotional } \\
\text { reactions when it comes to using } \\
\text { the system }\end{array}$ \\
\hline ATT & $\begin{array}{l}\text { Attitude } \\
\text { towards } \\
\text { technology }\end{array}$ & $\begin{array}{l}\text { Positive or negative feelings about } \\
\text { the appliance of the technology }\end{array}$ \\
\hline FC & $\begin{array}{l}\text { Facilitating } \\
\text { conditions }\end{array}$ & $\begin{array}{l}\text { Factors in the environment that } \\
\text { facilitate use of the system }\end{array}$ \\
\hline ITU & $\begin{array}{l}\text { Intention to } \\
\text { Use }\end{array}$ & $\begin{array}{l}\text { The intention to use the system } \\
\text { over a longer period in time }\end{array}$ \\
\hline PAD & $\begin{array}{l}\text { Perceived } \\
\text { adaptiveness }\end{array}$ & $\begin{array}{l}\text { The perceived ability of the system } \\
\text { to adapt to the needs of the user }\end{array}$ \\
\hline PENJ & $\begin{array}{l}\text { Perceived } \\
\text { Enjoyment }\end{array}$ & $\begin{array}{l}\text { Feelings of joy/pleasure associated } \\
\text { with the use of the system }\end{array}$ \\
\hline PEOU & $\begin{array}{l}\text { Perceived } \\
\text { Ease of Use }\end{array}$ & $\begin{array}{l}\text { The degree to which one believes } \\
\text { that using the system would be free } \\
\text { of effort }\end{array}$ \\
\hline PS & $\begin{array}{l}\text { Perceived } \\
\text { Sociability }\end{array}$ & $\begin{array}{l}\text { The perceived ability of the system } \\
\text { to perform sociable behavior }\end{array}$ \\
\hline PU & $\begin{array}{l}\text { Perceived } \\
\text { Usefulness }\end{array}$ & $\begin{array}{l}\text { The degree to which a person } \\
\text { believes that the system would be } \\
\text { assistive }\end{array}$ \\
\hline SI & $\begin{array}{l}\text { Social } \\
\text { Influence }\end{array}$ & $\begin{array}{l}\text { The persons perception that people } \\
\text { who are important to him think he } \\
\text { should or should not use the system }\end{array}$ \\
\hline SP & $\begin{array}{l}\text { Social } \\
\text { Presence }\end{array}$ & $\begin{array}{l}\text { The experience of sensing a social } \\
\text { entity when interacting with the } \\
\text { system }\end{array}$ \\
\hline Trust & Trust & $\begin{array}{l}\text { The belief that the system performs } \\
\text { with personal integrity and } \\
\text { reliability }\end{array}$ \\
\hline Use & Use & $\begin{array}{l}\text { The actual use of the system over a } \\
\text { longer period in time }\end{array}$ \\
\hline
\end{tabular}

than office environment (see Table 1 for construct definitions and Table 2 for the items that were included). However, when rephrasing the items, we tried to stay as close to the original form as possible. The constructs Performance Expectancy, Effort Expectancy (renamed Perceived Usefulness and Perceived Ease of Use to suit the home rather than work environment), Social Influence, Facilitating Conditions, Intention to Use and Actual Use were adapted for the used questionnaire. We also included Anxiety, and Attitude toward using the technology: although they were not included in the UTAUT model, several other studies found these factors directly influential [31-34]. Moreover, we were interested in measuring elderly participants' levels of Anxiety and Attitude toward the assistive social agent.

\subsection{Additional Constructs}

Perceived Enjoyment Previous literature reports that perceived enjoyment with a computer system positively affects
Table 2 Used questionnaire

ANX

If I should use the robot, I would be afraid to make mistakes with it

If I should use the robot, I would be afraid to break something

I find the robot scary

I find the robot intimidating

ATT

I think it's a good idea to use the robot

The robot would make life more interesting

It's good to make use of the robot

FC

I have everything I need to use the robot

I know enough of the robot to make good use of it

ITU

I think I'll use the robot during the next few days

I'm certain to use the robot during the next few days

I plan to use the robot during the next few days

PAD

I think the robot can be adaptive to what I need

I think the robot will only do what I need at that particular moment

I think the robot will help me when I consider it to be necessary

PENJ I enjoy the robot talking to me

I enjoy doing things with the robot

I find the robot enjoyable

I find the robot fascinating

I find the robot boring

PEOU I think I will know quickly how to use the robot

I find the robot easy to use

I think I can use the robot without any help

I think I can use the robot when there is someone around to help me

I think I can use the robot when I have a good manual

I consider the robot a pleasant conversational partner

I find the robot pleasant to interact with

I feel the robot understands me

I think the robot is nice

PU

I think the robot is useful to me

It would be convenient for me to have the robot I think the robot can help me with many things

I think the staff would like me using the robot

I think it would give a good impression if I should use the robot

SP

When interacting with the robot I felt like I'm talking to a real person

It sometimes felt as if the robot was really looking at me

I can imagine the robot to be a living creature

I often think the robot is not a real person

Sometimes the robot seems to have real feelings

Trust I would trust the robot if it gave me advice

I would follow the advice the robot gives me 
an individual's behavioral intentions towards usage [35-38]. In evaluating social agents such as companion type robots, an element of pleasure when interacting with the agent may very well influence user acceptance. Van der Heijden [38] points out that in 'hedonic systems' the concept of enjoyment is a crucial determinant for the intention to use these systems. Of course, social agents in eldercare will hardly be developed just to entertain: they will be partly utilitarian, partly hedonic. But even if just partly hedonic, enjoyment is found to be a construct that needs to be part of an acceptance model for robotic technology [36]. And even in utilitarian systems Perceived Enjoyment can be a relevant influencing factor, as pointed out in an extensive study by Sun and Zhang [37]. This study supports the claims that Perceived Enjoyment influences Ease of Use rather than being a consequence of it, as claimed by some other studies. A study we performed and reported on previously confirms this and establishes Perceived Enjoyment as an influence both on Perceived Ease of Use and directly on Intention to Use [39]. The perceived enjoyment items (Table 2) were adapted from [35].

Social Presence Since it is not unusual for humans to engage with technology as if it were a social entity [19], it can be expected that this effect is exacerbated when technology takes the form of an embodied character and interacts in a social manner using natural language and non-verbal human behaviors. The term presence refers to two different phenomena. First, it relates to the feeling of really being present in a virtual environment and can be defined as the sense of being there [40]. Second, it can relate to the feeling of being in the company of a social entity: the perceptual illusion of non-mediation [41]. In our context, the second definition is relevant since the extent to which one feels to be dealing with a social entity when meeting a robot or screen agent is of influence on the way it is perceived and accepted [23, 42]. Regarding the close connection between social abilities and the sense of presence [43], we incorporate social presence in our experiments to research its role and establish the influence of social abilities on it. We expect, based on previous findings [43], that the sense of presence increases if a system is perceived to have more social abilities, and that Perceived Enjoyment increases when this sense of presence is felt more intensely. To include this construct in the model, a set of 5 items were developed, adapted from [44].

Perceived Sociability This construct was formed based on our findings in previous studies [45] which are supported by related studies [46, 47]: our construct of perceived sociability may be unique as a part of an acceptance model, the need for social abilities for robots to function as assistive devices has been established in earlier studies as well as the need for social acceptance of robots and screen agents. We confirmed this in our earlier study, where we added questions on presumed social abilities to a list of UTAUT based questions, asked to older adults that just used an assistive social robot [48]. We found that the scores on the construct formed by these added questions correlated with all UTAUT constructs demonstrating that it relates to aspects of acceptance. We confirmed these findings in a later experiment, where we found the construct to be a determining influence on Social Presence and Perceived Enjoyment. Furthermore, we established that Trust (see next paragraph) has influence on this construct. The questionnaire items for Perceived Sociability were based on the items that proved to be a solid construct in our previous research $[45,48]$.

Trust The concept of Trust not only emerged from our own findings [29], it is also found in studies concerning robot technology $[31,49,50]$ and human-robot interaction [25, 30, 51]. To incorporate Trust into the model, two items were developed to measure the trust the user has in the robot and to what extent the user intends to comply to the robot's advice and on the nature of human-robot interaction. In the above mentioned studies, Trust is claimed to have a direct influence on Intention to Use but in both types of studies, it is also related to either social abilities or social behavior: a robot or screen agent with more social abilities is supposed to gain more trust by its users.

Perceived Adaptivity A particular feature of most chronic conditions that elderly people that need care suffer from is that their conditions change over time. Mobility may improve after a hip replacement, heart condition may deteriorate or improve after changes in medication, eyesight, hearing and dementia may become worse over time. Therefore, requirements for the type of support that is needed change over time. Intelligent assistive technology would need to adapt to these changes in conditions in order to provide appropriate support. Previous studies that address elderly users argue that adaptiveness is an essential aspect of technology that is developed for aging users [52, 53]. Forlizzi et al. included adaptivity in her design guidelines for robotic products that 'support the ecology of aging' [54]. It is expected that when users perceive the system to adapt to their changing needs, they will find it more useful and will be more accepting towards the system.

\subsection{Overview of Construct Interrelations}

Summarizing our assumptions as described above, we identified 11 constructs as potential direct determinants of Intention to Use or Actual Usage. Of these constructs, we theorize 7 to play a significant role as direct determinants of Intention to Use and Actual Usage: Perceived Usefulness, Perceived ease of Use, Perceived Enjoyment, Trust, Attitude, Social Influence and Facilitating Conditions. Anxiety, Perceived Sociability, Perceived Social Presence and perceived 
Fig. 4 Hypothetical construct interrelations

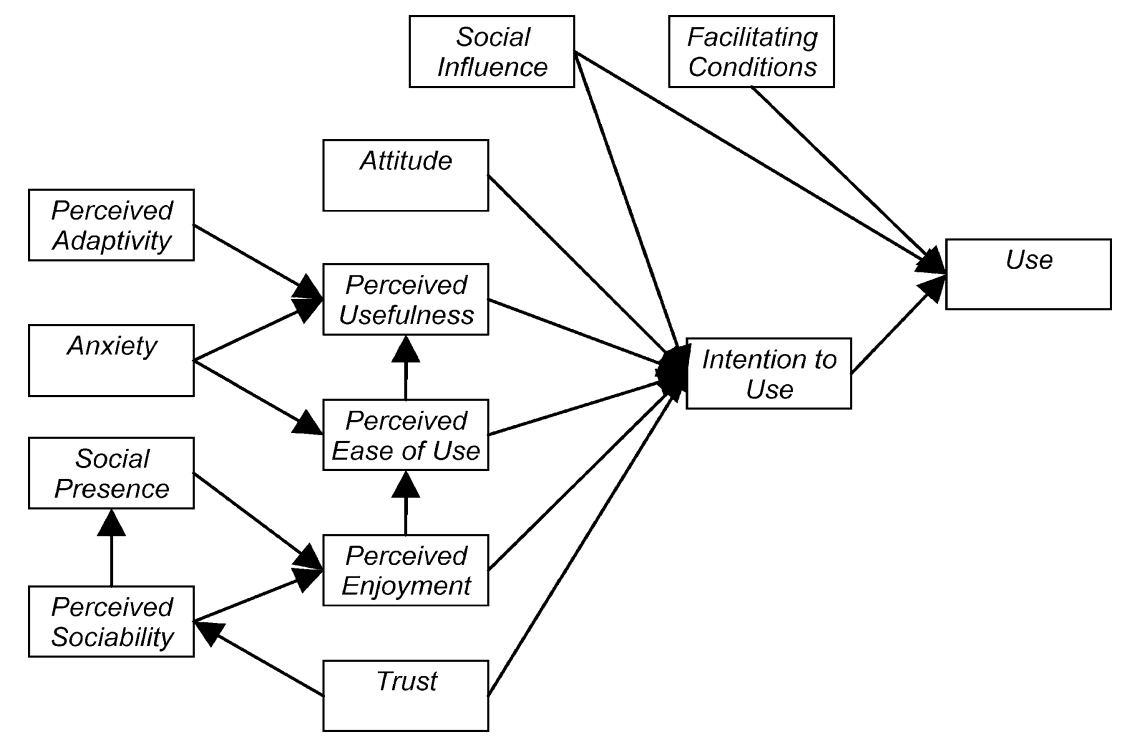

Adaptivity are theorized not to be direct determinants of Intention to Use. Figure 4 visualizes this model, featuring the following hypothetical construct interrelations that will be tested in our experiments:

1. Use is determined by (a) Intention to Use and influenced by (b) Social Influence and (c) Facilitating Conditions.

2. Intention to Use is determined by (a) Perceived Usefulness, (b) Perceived Ease of Use, (c) Attitude, (d) Perceived Enjoyment, (e) Social Influence and (f) Trust.

3. Perceived Usefulness is determined by (a) Perceived Ease of Use (b) Perceived Adaptability and (c) Anxiety.

4. Perceived Ease of Use is determined by (a) Anxiety and (b) Perceived Enjoyment.

5. Perceived Enjoyment is determined by (a) Perceived Sociability and (b) Social Presence.

6. Perceived Sociability is determined by Trust.

7. Social Presence is determined by Perceived Sociability.

Since most of the experiments have been carried out in the Dutch city of Almere (either in eldercare institutions or at the homes of older adults still living independently), we decided to honor our participants and collaborating staff by naming the model after this city.

\section{Experiments}

This section reports the results of four experiments that each focused on the validation of a different part of the model. The first experiment evaluates the influence of the social constructs: Social Presence, Perceived Sociability and Trust in an experiment that compared responses to a robot in a more social versus less social condition. We expected the differences in these responses to justify the presence of these constructs. The second experiment evaluates the influence of
Perceived Adaptivity in an experiment that exposes elderly participants to a short movie of a robot in a more versus less adaptive condition. We expected the differences in responses to the conditions to relate to the score on Perceived Adaptiveness. The third and fourth experiment evaluated the prediction of Actual Usage (first hypothesis in Sect. 3.3), which is needed to fully validate the model. We evaluated both a robot used in a public setting ('public use') and a screen agent used at the homes of the participants ('private use').

In these experiments, different systems (robots as well as screen agents) were evaluated and different settings were used (video trial, real robots, both at participant's homes and at eldercare institutions) which would benefit the possibility to generalize our findings.

In the analysis of the data we use regression analysis to see if the model fits the data collected. Furthermore, for each experiment we establish the $R^{2}$ value of the regression on Intention to Use and if applicable on Use, which can be used as an indication for the predictive strength. The value is between 0 and 1 , meaning that 0.50 indicates that $50 \%$ of the variation of a dependent variable is explained by the predicting variables. On the combined data we will carry out a confirmative and exploratory path analysis and establish the 'goodness of fit' of the final model.

The data collection instrument consisted of 41 items on a 5 point Likert-type scale ranging from 1 to 5 (totally disagree - disagree - don't know - agree - totally agree). The items (see Table 2) were presented in a random order to the participants. This order was the same for each experiment.

\subsection{Experiment 1: the Influence of Social Abilities}

Methodology In Experiment 1, elderly users interacted with the iCat robot. The manipulation concerned social expressiveness (socially expressive versus neutral), which was 


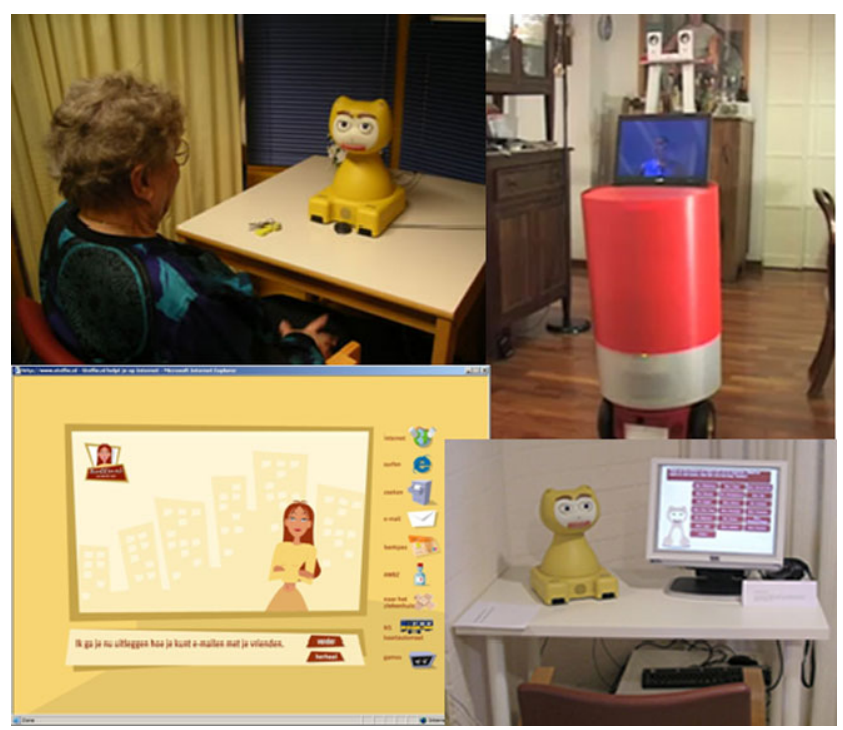

Fig. 5 Used systems, clockwise: iCat speech controlled, RoboCare (video), iCat with touch screen and Steffie

manipulated through the robot's verbal and non-verbal behavior. The socially expressive condition used the participant's name in its communication, kept eye-contact with the participant and apologized for its mistakes.

The experiment involved 40 participants between 65 and 89 years old; 18 were male and 22 female. Exactly half $(N=$ 20) of the participants were exposed to the social expressive condition and the other half to the neutral condition.

The robot used in this study was the iCat. It is not mobile and has a cartoon cat-like appearance, with movable lips, eyes, eyelids and eyebrows to display different facial expressions. There is a camera installed in its nose and the base contains two microphones [55]. Participants could interact freely by speaking with the iCat (Fig. 5). The iCat responded with pre-program-med sentences, controlled by an operator in a Wizard of Oz experimental set-up. The iCat's facial expressions were linked to the sentences the robot could speak. Gaze was either straight ahead (neutral condition) or tracking the user (socially expressive condition).

During the experiment the participants were introduced to the robot in groups of 4 or 8 , by a researcher. They were given a brief introduction by the robot itself about its capabilities (it can function as an interface to domestic applications, monitor its users, offer companionship, provide information, keep an agenda and remind the user to take medication). The researcher then explained the procedure of the individual experiment sessions that followed. Each participant interacted individually with the iCat for approximately 3 minutes. During this interaction the iCat could set an alarm, give the weather forecast or give directions to the nearest supermarket. Afterwards, participants completed the questionnaire.
Table 3 Cronbach's Alpha experiment 1

\begin{tabular}{llll}
\hline Construct & Alpha & Construct & Alpha \\
\hline ANX & 0.716 & PEOU & 0.765 \\
ATT & 0.790 & PS & 0.885 \\
FC & 0.846 & PU & 0.865 \\
ITU & 0.901 & SI & 0.752 \\
PAD & 0.740 & SP & 0.831 \\
PENJ & 0.846 & TRUST & 0.820 \\
\hline
\end{tabular}

Table 4 T-Test results on more and less social conditions

\begin{tabular}{lcll}
\hline Construct & $\mathrm{T}$ & Construct & $\mathrm{T}$ \\
\hline ANX & 0.148 & PEOU & 0.855 \\
ATT & -0.717 & PS & $2.208^{*}$ \\
FC & -0.230 & PU & 0.968 \\
ITU & $2.264^{*}$ & SI & 0.342 \\
PAD & 0.000 & SP & $2.271^{*}$ \\
PENJ & $2.027^{*}$ & TRUST & 0.143 \\
\hline
\end{tabular}

${ }^{*} p<0.05$

Our calculation of Cronbach's Alpha shows that reliability of the constructs was high (Table 3).

Detailed description of the methodology and results of this study can be found in [56].

Results Table 4 shows the t-test scores to compare the two conditions. Participants have more intention to use the robot in the socially expressive $(M=3.166, S D=0.820)$ compared with the neutral condition $(M=2.516, S D=0.988)$; Perceived sociability, Perceived Social Presence and Enjoyment were also higher in the socially expressive condition. This confirms that a more social robot is perceived as such and suggests that it is enjoyed more.

Table 5 shows the outcome of a regression analysis on the results related to the hypotheses, including the $R^{2}$ value. Intention to Use the robot is predicted by Perceived Ease of Use and Perceived Enjoyment, while the influence of other constructs could not be confirmed. It may be that the focus on a friendly 'chit-chat'-like interaction with the iCat influenced this focus on comfort rather than on competence related factors. In addition, the functionalities were more entertainment than service oriented. Hypothesis 2 could thus only be partially confirmed. Hypothesis 1 (ITU, SI and FC determine Use) was not included in this analysis because actual voluntary use of the system over a longer time period was not tested in this experiment. Perceived Usefulness of the iCat was determined by Perceived Adaptivity of the system. Hypothesis 3 can therefore only be partially accepted. Hypotheses 4, 5, 6 and 7 can be fully accepted. 
Table 5 Regression analysis experiment 1

\begin{tabular}{|c|c|c|c|c|c|}
\hline Hypothesis & $\begin{array}{l}\text { Independent } \\
\text { variable }\end{array}$ & $\begin{array}{l}\text { Dependent } \\
\text { variable }\end{array}$ & Beta & $\mathrm{T}$ & $R^{2}$ \\
\hline $\mathrm{H} 2 \mathrm{a}$ & PU & ITU & 0.097 & 0.633 & 0.70 \\
\hline $\mathrm{b}$ & PEOU & & 0.435 & $3.619^{* *}$ & \\
\hline $\mathrm{c}$ & ATT & & -0.037 & -0.227 & \\
\hline $\mathrm{d}$ & PENJ & & 0.581 & $5.079^{* *}$ & \\
\hline $\mathrm{e}$ & SI & & -0.061 & -0.465 & \\
\hline $\mathrm{f}$ & TRUST & & 0.023 & 0.151 & \\
\hline $\mathrm{H} 3 \mathrm{a}$ & ANX & PU & -0.203 & -1.664 & \\
\hline $\mathrm{b}$ & PAD & & 0.650 & $5.506^{*}$ & \\
\hline $\mathrm{c}$ & PEOU & & 0.118 & 0.879 & \\
\hline $\mathrm{H} 4 \mathrm{a}$ & ANX & PEOU & -0.430 & $-0.3 .259^{* *}$ & \\
\hline $\mathrm{b}$ & PENJ & & 0.375 & $2.854^{*}$ & \\
\hline H5a & PS & PENJ & 0.526 & $3.900^{* *}$ & \\
\hline $\mathrm{b}$ & SP & & 0.331 & $2.454^{*}$ & \\
\hline H6 & TRUST & PS & 0.320 & $2.083^{*}$ & \\
\hline H7 & PS & SP & 0.540 & $3.399^{* * *}$ & \\
\hline
\end{tabular}

${ }^{*} p<0.05$

${ }^{* *} p<0.005$

The findings of this study indicate that the socially expressive iCat was indeed found to be more sociable and to evoke more social presence. Moreover, participants found the socially expressive robot more enjoyable and they had a higher intention to use the robot. Regression analysis indicates a partial fit of the model with the data collected in this study and it results in an $R^{2}$ value of 0.70 , which is satisfactory.

\subsection{Experiment 2: Exploring Adaptivity}

Methodology In the second experiment, elderly users watched a video of the RoboCare robot. Although the experience of interaction with a real life robot obviously differs from viewing a robot featuring in a video, the literature indicates that video trials generally are recognized as a useful and valid methodology in HRI [57, 58]. The manipulation concerned adaptivity (an adaptive robot versus a non-adaptive robot). The short movie (approximately 5 minutes) featured a scenario with an elderly person who is assisted by the RoboCare robot. The robot is cylinder shaped and can move on wheels in its base (Fig. 5). It connects to an intelligent sensor and camera network. It can produce pre-programmed speech through a speaker. The version of the RoboCare robot used in this experiment is one equipped with a screen on which a female face is displayed to embody the conversation. The robot serves both as an interface to the 'smart home' technology and as an autonomous agent,
Table 6 Cronbach's Alpha experiment 2

\begin{tabular}{llll}
\hline Construct & Alpha & Construct & Alpha \\
\hline ANX & 0.701 & PEOU & 0.842 \\
ATT & 0.763 & PS & 0.717 \\
FC & 0.426 & PU & 0.825 \\
ITU & 0.854 & SI & 0.701 \\
PAD & 0.792 & SP & 0.735 \\
PENJ & 0.756 & TRUST & 0.758 \\
\hline
\end{tabular}

retrieving information from its intelligent environment and acting upon it [57]. The two movies were in Dutch with a simulated robotic female voice for the robot. In the movie, the robot would monitor the user and alarm a relative when necessary, assist in remembering to take the right medication at the right time and function as a fitness advisor.

Adaptivity of the robot was manipulated as follows: In the non-adaptive version, the robot would demonstrate its functionalities and the user would actively request a service. In the adaptive version, the robot would only provide a service when necessary. If, for example, the user would forget to take her medication, the robot would either propose to remind her next time or instead, pro actively start reminding her.

The experiment involved 88 participants of which 28 were male and 60 were female; 45 viewed the adaptive version, 43 the non adaptive. Participants were visited by a researcher who explained the procedure of the experiment, showed one of the movies on a laptop computer and administered the questionnaire.

Our calculation of Cronbach's Alpha shows that the reliability of the constructs was high (Table 6) except for Facilitating Conditions. This exception can be explained by the setting of the experiment: participants did not experience actual use of this robot and would just guess about what they would need and know and this could result in a far from solid construct.

Detailed description of the methodology and results of this study can be found in [59].

Results Table 7 shows the t-test scores comparing the conditions. Perceived adaptivity was indeed higher in the adaptive condition $(M=3.674, S D=0.566)$ compared with the non-adaptive condition $(M=3.302, S D=0.673)$. This indicates our manipulation was successful. Participants who saw the adaptive robot condition were found to have a higher intent to use the system, have a more positive attitude toward the robot, perceive the robot as more enjoyable and more useful. Participants in the adaptive condition also reported to feel more anxiety toward the robot and found other people's opinions about using the robot (social influence) more important. 
Table 7 T-Test results on more and less adaptive versions

\begin{tabular}{lrll}
\hline Construct & $\mathrm{T}$ & Construct & $\mathrm{T}$ \\
\hline ANX & $-2.334^{*}$ & PEOU & 1.150 \\
ATT & $3.023^{*}$ & PS & 0.306 \\
FC & 0.150 & PU & 3.523 \\
ITU & $3.485^{*}$ & SI & $2.178^{*}$ \\
PAD & $2.807^{*}$ & SP & 0.350 \\
PENJ & $2.298^{*}$ & TRUST & 1.655 \\
\hline
\end{tabular}

${ }^{*} p<0.05$

Table 8 Regression analysis experiment 2

\begin{tabular}{|c|c|c|c|c|c|}
\hline Hypothesis & $\begin{array}{l}\text { Independent } \\
\text { variable }\end{array}$ & $\begin{array}{l}\text { Dependent } \\
\text { variable }\end{array}$ & Beta & $\mathrm{T}$ & $R^{2}$ \\
\hline $\mathrm{H} 2 \mathrm{a}$ & PU & ITU & 0.330 & $3.642^{* *}$ & 0.68 \\
\hline $\mathrm{b}$ & PEOU & & 0.047 & 0.624 & \\
\hline $\mathrm{c}$ & ATT & & 0.496 & $5.442^{* *}$ & \\
\hline d & PENJ & & 0.031 & 0.375 & \\
\hline $\mathrm{e}$ & SI & & -0.015 & -0.192 & \\
\hline $\mathrm{f}$ & TRUST & & 0.086 & 1.096 & \\
\hline $\mathrm{H} 3 \mathrm{a}$ & ANX & $\mathrm{PU}$ & 0.006 & 0.056 & \\
\hline $\mathrm{b}$ & PAD & & 0.235 & $2.338^{*}$ & \\
\hline $\mathrm{c}$ & PEOU & & 0.365 & $3.264^{* *}$ & \\
\hline $\mathrm{H} 4 \mathrm{a}$ & ANX & PEOU & -0.334 & $-3.543^{* *}$ & \\
\hline $\mathrm{b}$ & PENJ & & 0.359 & $3.809^{* * *}$ & \\
\hline H5a & PS & PENJ & 0.419 & $3.449^{* *}$ & \\
\hline $\mathrm{b}$ & SP & & 0.169 & 1.433 & \\
\hline H6 & TRUST & PS & 0.571 & $6.445^{* *}$ & \\
\hline $\mathrm{H} 7$ & PS & SP & 0.632 & $7.565^{* *}$ & \\
\hline
\end{tabular}

${ }^{*} p<0.05$

${ }^{* *} p<0.005$

The results in Table 8 show that not all of the hypothesized effects are confirmed. Intention to use the robot is predicted by Perceived Usefulness and Attitude. It may be that the focus on assistive tasks such as medicine reminders highlighted competence factors over comfort factors. Hypothesis 2 could therefore only be partially confirmed. Perceived Usefulness of the iCat was determined by Perceived Adaptivity and Perceived Ease of Use. Hypothesis 3 can therefore only be partially accepted. Hypothesis 4 can be fully accepted. Perceived Enjoyment was determined by Perceived Sociability. Thus, hypothesis 5 can only be partially accepted. Hypotheses 6 and 7 can be fully accepted.

The findings of this study indicate that the adaptive RoboCare was rated more positively, indicating that adaptivity is indeed a demand that motivates this user group to accept assistive technology. In contrast, participants felt more anxiety towards the adaptive robot-possibly because they felt less in control of it. Also they scored higher on Social Influence which can be attributed to the interpretation of this item in this non-working environment: they enjoy the robot and would like to share this with caretakers and others. Regression analysis indicates a partial fit of the model with the data collected in this study and it results in an $R^{2}$ value of 0.68 , which is satisfactory.

\subsection{Experiment 3: Actual Public Use}

Methodology This experiment measured Actual Use over a one week time period. Participants could use the iCat in a public place during an entire week after a short individual interaction. Other variables are those defined in the research model in the previous section. The iCat used in this experiment was not controlled in a Wizard of Oz set up as in experiment 1 . Instead of speaking directly to the iCat, participants could interact with it through a touch screen interface. This was a different system setup from experiment 1 , but we did not see this as an objection, especially since we were not specifically testing the iCat robot-and actually many service type robots do have a touch screen interface [4].

Participants could ask for the weather forecast, an overview of television programs or listen to a joke by pressing the appropriate choices from the menu on the screen. The robot spoke with pre-recorded speech, for which we used a computer generated female voice produced by a text to speech engine.

The sample consisted of 30 participants. Their age ranged from 65 to $94 ; 22$ were female and 8 were male. They lived in an elderly residence, either in private rooms or independently in apartments. During the experiment participants were introduced to the iCat and instructed to simply play around with it for approximately three minutes. Subsequently they filled in the questionnaire in a separate room. After these sessions were completed, the robot was left in the tea room for residents to use. On the screen were buttons with the names of the test session participants and one extra button saying "I'm not listed". Passers-by were informed by a note that anyone was allowed to use the robot and that they could start a session by pressing the button with their name on it or the "I'm not listed" button if their name was not on the screen. When a user started using the robot, a video recording of the user was made through the camera in the robot's nose. The start and end times of each individual user session were logged. By comparing the video footage to the usage log, we could later check which participant belonged to each interaction setting (anyonepassing by could have clicked on a name).

Our calculation of Cronbach's Alpha shows that reliability of the constructs was high (Table 9). 
Table 9 Cronbach's Alpha experiment 3

\begin{tabular}{llll}
\hline Construct & Alpha & Construct & Alpha \\
\hline ANX & 0.854 & PEOU & 0.720 \\
ATT & 0.801 & PS & 0.786 \\
FC & 0.706 & PU & 0.787 \\
ITU & 0.947 & SI & 0.793 \\
PAD & 0.834 & SP & 0.866 \\
PENJ & 0.836 & TRUST & 0.802 \\
\hline
\end{tabular}

Table 10 Regression analysis experiment 3

\begin{tabular}{|c|c|c|c|c|c|}
\hline Hypothesis & $\begin{array}{l}\text { Independent } \\
\text { variable }\end{array}$ & $\begin{array}{l}\text { Dependent } \\
\text { variable }\end{array}$ & Beta & $\mathrm{T}$ & $R^{2}$ \\
\hline $\mathrm{H} 1 \mathrm{a}$ & ITU & Use & 0.671 & $4.603^{* *}$ & 0.49 \\
\hline $\mathrm{b}$ & SI & & 0.133 & 0.937 & \\
\hline $\mathrm{c}$ & FC & & -0.276 & -1.909 & \\
\hline $\mathrm{H} 2 \mathrm{a}$ & PU & ITU & 0.094 & 0.510 & 0.63 \\
\hline $\mathrm{b}$ & PEOU & & 0.545 & $3.373^{* *}$ & \\
\hline $\mathrm{c}$ & ATT & & 0.437 & $1.946^{*}$ & \\
\hline d & PENJ & & -0.078 & -0.347 & \\
\hline $\mathrm{e}$ & SI & & -0.225 & -1.491 & \\
\hline f & TRUST & & 0.044 & 0.223 & \\
\hline $\mathrm{H} 3 \mathrm{a}$ & ANX & PU & -0.104 & -0.756 & \\
\hline $\mathrm{b}$ & PAD & & 0.486 & $3.214^{* *}$ & \\
\hline $\mathrm{c}$ & PEOU & & 0.433 & $3.013^{*}$ & \\
\hline $\mathrm{H} 4 \mathrm{a}$ & ANX & PEOU & 0.268 & 1.854 & \\
\hline $\mathrm{b}$ & PENJ & & 0.572 & $3.962^{* *}$ & \\
\hline H5a & PS & PENJ & 0.361 & $2.144^{* *}$ & \\
\hline $\mathrm{b}$ & SP & & 0.411 & $2.446^{*}$ & \\
\hline H6 & TRUST & PS & 0.418 & $2.435^{*}$ & \\
\hline $\mathrm{H} 7$ & PS & SP & 0.540 & $3.399^{* *}$ & \\
\hline
\end{tabular}

Detailed description of the methodology and the results of this study can be found in [60].

Results The results in Table 10 show that not all of the hypothesized effects are confirmed. Intention to use the robot is predicted by Perceived Ease of Use and Attitude. Hypothesis 2 could therefore only be partially confirmed. Hypothesis 1 could only be partially confirmed with Actual Use predicted by Intention to Use. Perceived Usefulness of the iCat was determined by Perceived Adaptivity only. Hypothesis 3 can therefore only be partially accepted. Hypothesis 4 can be partially accepted with Enjoyment predicting Perceived Ease of Use. Hypotheses 5, 6 and 7 can be fully accepted.
Table 11 Cronbach's Alpha experiment 4

\begin{tabular}{llll}
\hline Construct & Alpha & Construct & Alpha \\
\hline ANX & 0.812 & PEOU & 0.726 \\
ATT & 0.851 & PS & 0.878 \\
FC & 0.707 & PU & 0.865 \\
ITU & 0.948 & SI & 0.794 \\
PAD & 0.709 & SP & 0.816 \\
PENJ & 0.774 & TRUST & 0.732 \\
\hline
\end{tabular}

The findings of this study show that Actual Use of the robot is indeed predicted by the participant's Intention to Use the robot. Similarly to the findings of experiment 1 where the iCat was voice operated, Intention to Use is determined by Perceived Ease of Use. Similarly to experiment 2, Attitude also determines Intention to Use. Furthermore, the regression analysis results in an $R^{2}$ value of 0.68 for Intention to Use, which is satisfactory, and 0.49 for Use, which is lower, but also satisfactory.

\subsection{Experiment 4: Actual Private Use}

Methodology This experiment measured actual use of an on screen virtual character. Participants were able to interact with Steffie, a virtual screen character designed to assist elderly in using the internet, e-mail, health insurance, cash dispensers and railway ticket machines. Steffie speaks and uses both facial expressions and gestures. The user communicates with Steffie through a graphical user interface menu with clicking options that are used for choosing subjects, to let her continue or to let her repeat. Steffie is developed as a part of an informative website (www.steffie.nl).

An offline version of the Steffie application was installed on the personal computers of the participants. We added a $\log$ in page with the names of the users. Once the user chose his or her name to start using Steffie, the session was recorded in a log file.

Participants were 30 elderly users, aged 65 to 89,14 female and 16 male, who owned a computer. They were visited by a researcher who installed the application on their pc. The basic functionality of the application was explained and participants tried out the application for approximately three minutes. Afterwards they filled in the questionnaire. After ten days, the researcher returned to close the experiment and copy the log file.

Our calculation of Cronbach's Alpha shows that reliability of the constructs was high (Table 11).

Detailed description of the methodology and the results of this study can be found in [61].

Results The results in Table 12 show that not all of the hypothesized effects are confirmed. Intention to use the robot 
Table 12 Regression analysis experiment 4

\begin{tabular}{|c|c|c|c|c|c|}
\hline Hypothesis & $\begin{array}{l}\text { Independent } \\
\text { variable }\end{array}$ & $\begin{array}{l}\text { Dependent } \\
\text { variable }\end{array}$ & Beta & $\mathrm{T}$ & $R^{2}$ \\
\hline H1a & ITU & Use & 0.945 & $5.700^{* *}$ & 0.59 \\
\hline $\mathrm{b}$ & SI & & -0.420 & $-2.553^{*}$ & \\
\hline c & FC & & -0.327 & $-2.576^{*}$ & \\
\hline $\mathrm{H} 2 \mathrm{a}$ & PU & ITU & 0.616 & $3.301^{* *}$ & 0.79 \\
\hline $\mathrm{b}$ & PEOU & & -0.114 & -0.794 & \\
\hline c & ATT & & 0.491 & $2.228^{*}$ & \\
\hline d & PENJ & & -0.125 & -0.668 & \\
\hline $\mathrm{e}$ & SI & & 0.015 & 0.105 & \\
\hline $\mathrm{f}$ & TRUST & & 0.011 & 0.067 & \\
\hline $\mathrm{H} 3 \mathrm{a}$ & ANX & PU & 0.337 & $2.452^{*}$ & \\
\hline $\mathrm{b}$ & PAD & & 0.325 & $2.471^{*}$ & \\
\hline c & PEOU & & 0.413 & $2.772^{*}$ & \\
\hline $\mathrm{H} 4 \mathrm{a}$ & ANX & PEOU & 0.268 & 1.854 & \\
\hline $\mathrm{b}$ & PENJ & & 0.572 & $3.962^{* *}$ & \\
\hline H5a & PS & PENJ & 0.686 & $4.259^{* *}$ & \\
\hline $\mathrm{b}$ & SP & & 0.097 & 0.600 & \\
\hline H6 & TRUST & PS & 0.608 & $4.057^{* *}$ & \\
\hline $\mathrm{H} 7$ & PS & SP & 0.609 & $4.067^{* *}$ & \\
\hline
\end{tabular}

* $p<0.05$

** $p<0.005$

is predicted by Usefulness and Attitude. Hypothesis 1 could therefore only be partially confirmed. Hypothesis 2 and 3 could be fully accepted. Hypothesis 4 can be partially accepted with Enjoyment predicting Perceived Ease of Use. Hypothesis 5 can only be partially accepted with Perceived Sociability predicting Enjoyment. Hypotheses 6 and 7 can be fully accepted.

Furthermore, the regression analysis results in an $R^{2}$ value of 0.79 for Intention to Use, which is exceptionally high, and 0.59 for Use, which is also satisfactory.

\section{The Final Almere Model}

The systems used in the experiments were very different and experiment 2 confronted participants not even with an actual system but with videos of a robot. Nevertheless, in all experiments we used the same questionnaire. Moreover, the assumption is that the model is applicable to different systems and conditions. This means that despite these different systems and settings, we can add the results of the experiments, thus obtaining a set of data with 188 cases (total number of participants in all 4 experiments). This gives us the possibility to apply structural equation modeling, a type of analysis in which the whole model can be tested at once instead of

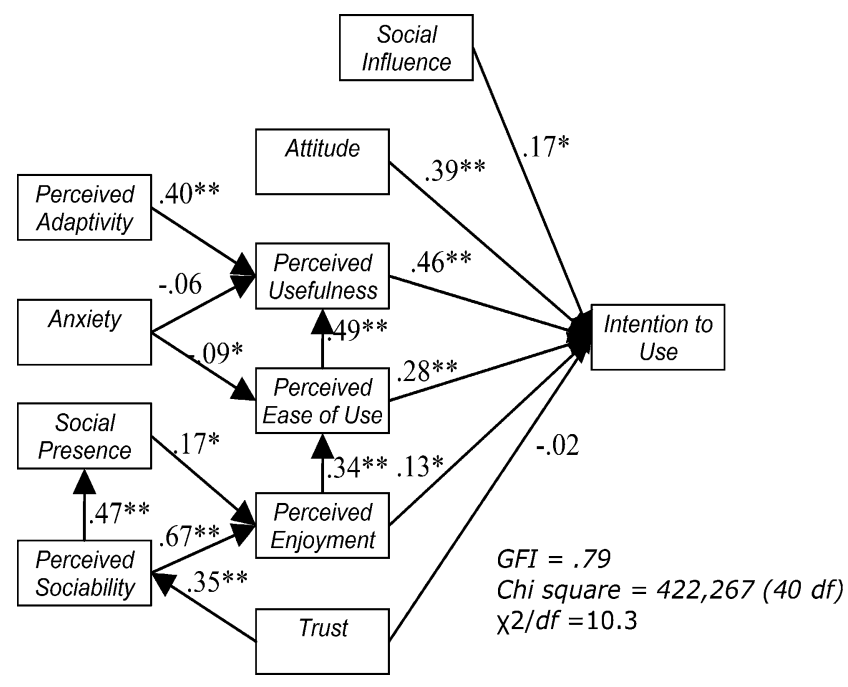

Fig. 6 Initial model path estimates $\left({ }^{*} p<0.05,{ }^{* *} p<0.005\right)$

Table 13 Modification indices

\begin{tabular}{lc}
\hline Construct interrelations & Modification indices \\
\hline ATT $\leftarrow$ SI & 48.325 \\
ATT $\leftarrow$ ANX & 6.183 \\
ATT $\leftarrow$ PAD & 28.612 \\
Trust $\leftarrow$ ATT & 48.830 \\
\hline
\end{tabular}

the individual hypotheses. Usually this requires 15 cases per variable [62] which means in our case we need at least 150 cases.

Executing a path analysis with structural equation modeling on our model, using the statistical package SPSS AMOS leads to the results pictured in Fig. 6. It shows that all of the construct interrelations have significant weights, except for Anxiety determining Perceived Usefulness and Trust determining Intention to Use (which has not been confirmed by any regression analysis). Figure 6 also presents the Chisquare, the degrees of freedom (66 sample moments minus 26 estimated parameters) and the goodness-of-fit index (GFI), which indicates how well the data set fits the model. This GFI of 0.79 is quite low, it is recommended to have it close to 0.90 [63] and chi-square divided by degree of freedom $\left(\chi^{2} / d f\right)$ should be below 5 [64], which is also not the case. This made us explore other not yet established construct interrelations that would be plausible and would raise the GFI. A common way to do such an exploratory path analysis, is by calculating modification indices $[65,66]$, which can also be done with SPSS AMOS. A value in these modification indices above 3.84 suggests that adding that path may significantly improve model fit [67], since 3.84 is the critical value of the chi-square statistic with 1 degree of freedom at the 5\% significance level. Table 13 shows modification indices we found to fit this criterion for in- 
terrelations that were plausible: Social Influence, Perceived Adaptiveness and Anxiety determining Attitude and for Attitude determining Trust. When applying these suggested relations to our model we found highly significant weight scores $(p<0.005)$. We carried out an additional linear regression analysis for these new interrelations. The results are presented in Table 14. Figure 7 shows the model dia-

Table 14 Additional interrelations

\begin{tabular}{llll}
\hline Independent & Dependent & Beta & $\mathrm{t}$ \\
\hline PAD & ATT & 0.249 & $3.927^{* *}$ \\
SI & & 0.423 & $6.682^{* *}$ \\
ANX & & 0.178 & $2.984^{* *}$ \\
ATT & Trust & 0.511 & $8.108^{* *}$ \\
\hline
\end{tabular}

${ }^{*} p<0.05$

** $p<0.005$ gram with the construct interrelations confirmed by regression analyses including the additional interrelations for the four experiments.

Figure 8 shows the updated model diagram with the path analysis including the additional interrelations. It now has a GFI of 0.96, which is high (note that $d f$ is now 66 sample moments minus 29 estimated parameters).

All hypothetical construct interrelations have been confirmed at some point, either by a linear regression analysis or by path analysis, except for the impact of Trust on Intention to Use, which has never been confirmed and is left out of the final model.

\section{Discussion}

The final model has predictive strength and constructs that have proven to be solid in various settings. It did show robustness during quantitative analysis and we have seen a
Fig. 7 Final model: interrelations confirmed by regression scores for the experiments. The numbers refer to: 1 iCat speech controlles, 2 Robocare videos, 3 iCat touch screen, 4 Screen agent Steffie. Dotted line: not confirmed by any regression analysis

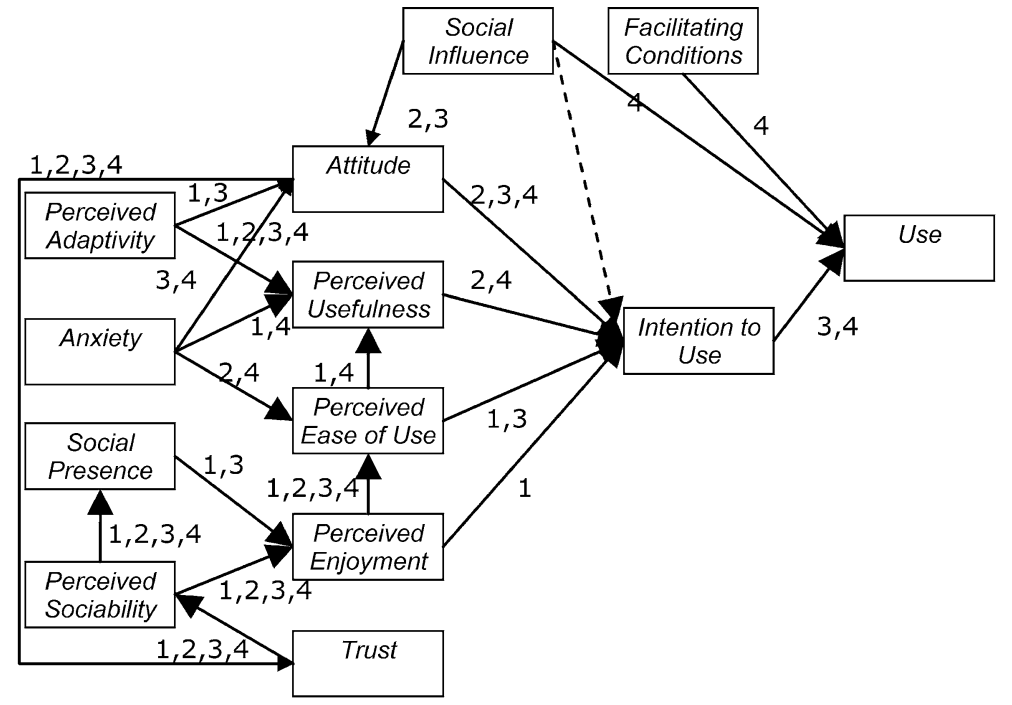

Fig. 8 Final model path estimates $\left({ }^{*} p<0.05\right.$, $\left.{ }^{* *} p<0.005\right)$

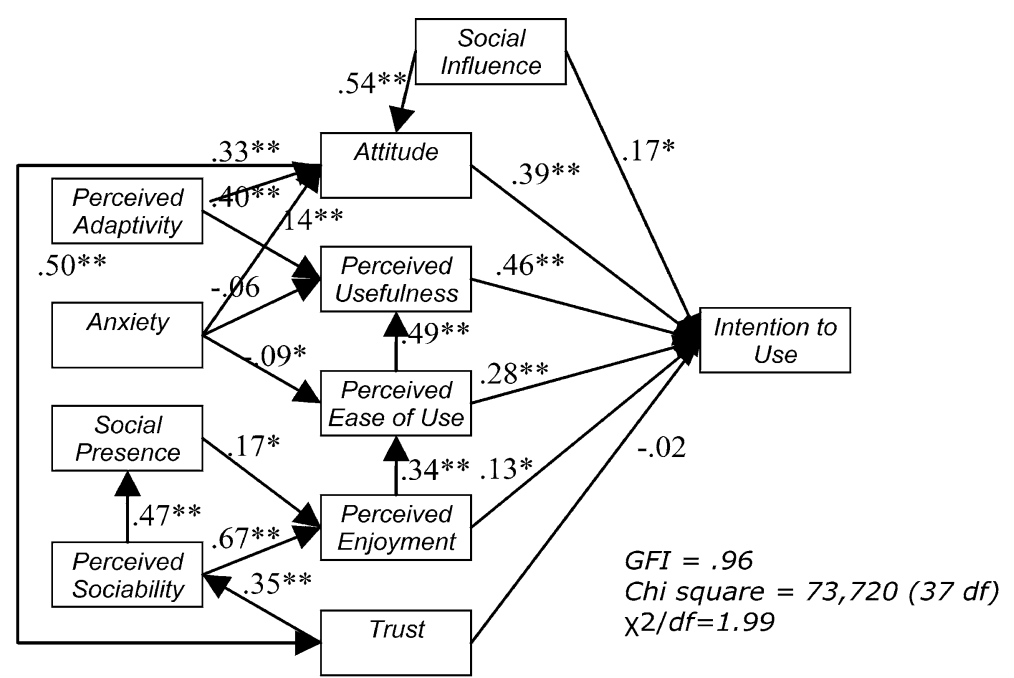


satisfying goodness of fit score on our data. We have thus developed a model that can be used to predict and explain acceptance of assistive social robots. If applied to different systems and settings it results in a difference in dominating influences that can explain the impact of these differences. It has demonstrated that the influential strength of the processes that lead to acceptance differ between systems, which confirms findings of Van der Heijden [35] and Chesney [36] that the purpose of use is essential in determining the factors that predict acceptance. In addition, our model development process revealed the importance of Attitude in this context. It was one of the most significant influences on Intention to Use in three of the four experiments and it appeared to have additional interrelations after our explanatory analysis in Sect. 5. With this finding we are consistent with that of Yang and Yoo [32], that Attitude is a crucial factor that needs further investigation and perhaps specification. Their idea that the there are different types of attitude (cognitive and affective) could in fact be applied very well to robot technology, because of its dual nature, combining technical and social entities.

Despite the excellent goodness of fit and predictive strength, in some aspects our model still needs further research before we can claim its completion. First of all, usage is just measured over a short period in experiments 3 and 4 . Studies involving a longer usage period (rather months than days or weeks) can give a more accurate impression of the actual use of this technology. Furthermore, although we used four different systems, it would be interesting to see the results of more studies with different assistive social robots that have features that our used systems lack. Also our study would benefit from an experiment that would include repetitive testing, which makes it possible to study factors that are often subject to change, like Attitude and Trust. Furthermore, as adults grow older and develop different needs, their attitude towards assistive technology in general and more specifically for an assistive social robot can change. This would, according to our model, lead to a change in Intention to Use: it would be interesting to see if this claim can be confirmed by long term research.

Finally, there is an area that we left untouched, but that could still become an accessory to our methodology: moderating factors. Age, gender, voluntariness and computer experience are personal characteristics that are known to be moderating the processes that determine acceptance. When added to our model, they could complete our developed vision on the acceptance of assistive social robots and screen agents.

Acknowledgements This work was supported in part by the Hogeschool van Amsterdam and in part by the European Commission Division FP6-IST Future and Emerging Technologies under Contract FP6002020 (Cogniron). We like to express our gratitude to the staff and caretakers as well as the test participants of De Kiekendief, De Overloop, De Archipel, De Uiterton and De Emtinckhof for their cooperation. Furthermore we are extremely greatfull for the participants that were willing to receive us at their homes. Also we like to thank Willem Notten, Bas Terwijn and Rogier Voors for their work on programming the system and Rick van Midde, Albert van Breemen and Martin Saerbeck for their support. Moreover we want to thank Ruud Smeulders, Rabobank Foundation, Netrex and Fons Kuijk of CWI for enabling us to work with Steffie and develop Annie, and Frederico Pecora for the RoboCare materials.

Open Access This article is distributed under the terms of the Creative Commons Attribution Noncommercial License which permits any noncommercial use, distribution, and reproduction in any medium, provided the original author(s) and source are credited.

\section{References}

1. United Nations (2007) World population prospects: the 2006 revision-comprehensive tables. United Nations Publications, New York

2. Pollack M (2005) Intelligent technology for an aging population: the use of AI to assist elders with cognitive impairment. AI Mag 26(2):9-24

3. Giuliani MS, Fornara F (2005) Coping strategies and technology in later life. In: Proceedings of AISB 2005, Hatfield

4. Zajicek M, Arnold A (1999) The 'technology push' and the user Tailored information environment. In: 5th European research consortium for informatics and mathematics, workshop on user interfaces for all

5. Broekens J, Heerink M, Rosendal H (2009) The effectiveness of assistive social robots in elderly care: a review. Gerontechnol J 8(2):94-103

6. Breazeal C (2003) Towards sociable robots. Robot Auton Syst 42(3-4)

7. Nomura T, Nakao A (2010) Comparison on identification of affective body motions by robots between elder people and university students: a case study in Japan. Int J Soc Robot 2(2):147-157

8. Davis FD (1989) Perceived usefulness, perceived ease of use, and user acceptance of information technology. Manag Inf Syst Q

9. Graf B, Hans M, Schraft RD (2004) Care-O-bot II development of a next generation robotic home assistant. Auton Robots 16(2):193-205

10. Yanco HA (2001) Development and testing of a robotic wheelchair system for outdoor navigation. In: Proceedings of the 2001 conference of the rehabilitation engineering and assistive technology society of North America

11. Guizzo E, Goldstein H (2005) The rise of the body bots [robotic exoskeletons]. IEEE Spectr 42(10):50-56

12. Scanaill CN, Carew S, Barralon P, Noury N, Lyons D, Lyons GM (2006) A review of approaches to mobility telemonitoring of the elderly in their living environment. Ann Biomed Eng 34(4):547563

13. DiSalvo C, Gemperle F, Forlizzi J, Montgomery E, Yonkers W, Divine J (2003) The hug: an exploration of robotic form for intimate communication. In: RO-MAN 03

14. Beck A, Edwards N, Friedman B, Khan P (2003) Robotic pets and the elderly. Available from: http://www.ischool.washington. edu/robotpets/elderly/

15. Jung JW, Do JH, Kim YM, Suh KS, Kim DJ, Bien ZZ (2005) Advanced robotic residence for the elderly/the handicapped: realization and user evaluation. In: 9th international conference on rehabilitation robotics (ICORR) 
16. Giuliani MV, Scopelliti M, Fornara F (2005) Elderly people at home: technological help in everyday activities. In: IEEE international workshop on robot and human interactive communication, ROMAN 2005, pp 365-370

17. Cesta A, Cortellessa G, Pecora F, Rasconi R (2007) Supporting interaction in the robo care intelligent assistive environment. In: Proceedings of AAAI spring symposium on interaction challenges for intelligent assistants, pp 18-25

18. Pollack ME, Brown L, Colbry D, Orosz C, Peintner B, Ramakrishnan S, Engberg S, Matthews JT, Dunbar-Jacob J, McCarthy CE, Thrun S, Montemerlo M, Pineau J, Pearl NR (2002) A mobile robotic assistant for the elderly. In: AAAI workshop on automation as eldercare

19. Shibata T, Wada K, Tanie K (2003) Statistical analysis and comparison of questionnaire results of subjective evaluations of seal robot in Japan and UK. In: Proceedings IROS 2003

20. Reeves B, Nass C (1996) The media equation: how people treat computers, televisions, and new media as real people and places. Cambridge University Press, New York

21. Stiehl WD, Lieberman J, Breazeal C, Basel L, Cooper R, Knight H, Lalla L, Maymin A, Purchase S (2006) The Huggable: a therapeutic robotic companion for relational, affective Touch. In: IEEE consumer communications and networking conference

22. Parlitz C, Baum W, Reiser U, Hagele M (2007) Intuitive humanmachine-interaction and implementation on a household robot companion. Lect Notes Comput Sci 4557:922-929

23. Bickmore T, Caruso L, Clough-Gorr K (2005) Acceptance and usability of a relational agent interface by urban older adults. In: Proceedings of the ACM SIGCHI conference on human factors in computing systems, Portland, USA

24. Bickmore T, Schulman D (2006) The comforting presence of relational agents. In: Proceedings of CHI

25. Bartneck C, Reichenbach J, van Breemen AJN (2004) In your face, robot! The influence of a character's embodiment on how users perceive its emotional expressions, design and emotion. In: Proceedings of the design and emotion 2004 conference, Ankara, Turkey

26. Shinozawa K, Naya F, Yamato J, Kogure K (2005) Differences in effect of robot and screen agent recommendations on human decision-making. Int J Hum Comput Stud 62(2):267-279

27. Fishbein M (1980) A theory of reasoned action: some applications and implications. Neb Symp Motiv 27:65-116

28. Fishbein M, Ajzen I (1975) Belief, attitude, intention, and behavior: an introduction to theory and research. Addison-Wesley, Reading

29. Venkatesh V, Morris MG, Davis GB, Davis FD (2003) User acceptance of information technology: toward a unified view. Manag Inf Syst Q 27(3):425-478

30. de Ruyter B, Saini P, Markopoulos P, van Breemen AJN (2005) Assessing the effects of building social intelligence in a robotic interface for the home. Soc Impact Emerg Technol 17(5):522-541

31. Wu I-L, Chen J-L (2005) An extension of trust and TAM model with TPB in the initial adoption of on-line tax: an empirical study. Int J HCS 62(6)

32. Yang H, Yoo Y (2004) It's all about attitude: revisiting the technology acceptance model. Decis Support Syst 38(1):19-31

33. Brown HG, Scott M, Deng PL, Forducey P (2005) Towards a sociability theory of computer anxiety: an interpersonal circumplex perspective. In: Proceedings of the 38th annual Hawaii international conference on system sciences

34. Nomura T, Suzuki T, Kanda T, Kato K (2006) Measurement of anxiety toward robots. In: Proceedings RO-MAN

35. Davis FD, Bagozzi RP, Warshaw PR (1992) Extrinsic and intrinsic motivation to use computers in the workplace. J Appl Soc Psychol 22:1111-1132

36. Chesney T (2006) An acceptance model for useful and fun information systems. Hum Technol 2(2):225-235
37. Sun H, Zhang P (2006) Causal relationships between perceived enjoyment and perceived ease of use: an alternative approach. J Assoc Inf Syst 7(9)

38. Van der Heijden $\mathrm{H}$ (2004) User acceptance of hedonic information systems. Manag Inf Syst Q 28(4):695-704

39. Heerink M, Kröse BJA, Wielinga BJ, Evers V (2008) Enjoyment, intention to use and actual use of a conversational robot by elderly people. In: Proceedings HRI 2008, Amsterdam, pp 113-120

40. Witmer BG, Singer MJ (1998) Measuring presence in virtual environments: a presence questionnaire. Presence 7(3):225-240

41. Lombard M, Ditton TB (1997) At the heart of it all: the concept of presence. J Comput-Mediat Commun 3(2). Available online: http://www.ascusc.org/jcmc/vol3/issue2/lombard.html

42. Lee KM, Nass C (2003) Designing social presence of social actors in human computer interaction. In: Proceedings of SIGCHI 2003

43. Heerink M, Kröse BJA, Wielinga BJ, Evers V (2008) The influence of social presence on enjoyment and intention to use of a robot and screen agent by elderly users. In: Proceedings RO-MAN, München

44. Bailenson JN, Blascovich J, Beall AC, Loomis JM (2001) Equilibrium revisited: mutual gaze and personal space in virtual environments. Presence Teleoperators Virtual Environ 10:583-598

45. Heerink M, Kröse B, Wielinga B, Evers V (2009) Measuring the influence of social abilities on acceptance of an interface robot and a screen agent by elderly users. In: Proceedings HCI 2009, Cambridge

46. Mitsunaga N, Miyashita Z, Shinozawa K, Miyashita T, Ishiguro H, Hagita N (2008) What makes people accept a robot in a social environment-discussion from six-week study in an office. In: IROS, Nice

47. Forlizzi J (2007) How robotic products become social products: an ethnographic study of cleaning in the home. In: ACM SIGCHI/SIGART human-robot interaction, pp 129-136

48. Heerink M, Kröse BJA, Wielinga BJ, Evers V (2006) Studying the acceptance of a robotic agent by elderly users. Int J Assist Robot Mechatron 7(3):33-43

49. Marsh S, Briggs P, Wagealla W (2004) Considering trust in ambient societies. In: Extended abstracts of the 2004 conference on human factors and computing systems

50. Cody-Allen E, Kishore R (2006) An extension of the UTAUT model with e-quality, trust, and satisfaction constructs. ACM, New York

51. Shinozawa K, Reeves B, Wise K, Lim S, Maldonado H, Naya F (2003) Robots as new media: a cross-cultural examination of social and cognitive responses to robotic and on-screen agents. In: Proceedings of the 53rd annual conference of the international communication association, information systems division, San Diego, CA, pp 998-1002

52. Camarinha-Matos LM, Afsarmanesh H (2002) Design of a virtual community infrastructure for elderly care. In: 3rd IFIP working conference on infrastructures for virtual enterprises. Kluwer, Dordrecht

53. Pew R, Hemel SV (2004) Technology for adaptive aging. National Academies Press, Washington

54. Forlizzi J, DiSalvo C, Gemperle F (2004) Assistive robotics and an ecology of elders living independently in their homes. J HCI, Special Issue on HRI 19(1/2):25-59

55. van Breemen A, Yan X, Meerbeek B (2005) iCat: an animated user-interface robot with personality. In: Proceedings of the fourth international joint conference on autonomous agents and multiagent systems, pp 143-144

56. Heerink M, Kröse BJA, Wielinga BJ, Evers V (2008) The influence of social presence on acceptance of a companion robot by older people. J Phys Agents 2(2):33-40

57. Bahadori S, Cesta A, Grisetti G, Iocchi L, Leone R, Nardi D, Oddi A, Pecora F, Rasconi R (2003) RoboCare: an integrated robotic 
system for the domestic care of the elderly. In: Proceedings of workshop on AI IA-03, Pisa, Italy

58. Woods S, Walters M, Koay KL Dautenhahn K (2006) Comparing human-robot interaction scenarios using live and video based methods: towards a novel methodological approach. In: Proceedings RO-MAN 2006, Hertfordshire

59. Heerink M (2009) Exploring adaptability, adaptivity and user control. Information Engineering Institute, Almere

60. Heerink M, Kröse B, Wielinga B, Evers V Measuring acceptance of an assistive social robot: a suggested toolkit. In: Proceedings RO-MAN 2009, Toyama, Japan

61. Heerink M (2008) Evaluating steffie. Information Engineering Institute, Almere

62. Gefen D, Straub D, Boudreau M (2000) Structural equation modeling and regression: guidelines for research practice. Struct Equ Model 4(7)

63. Tanaka JS (1987) "How big is big enough?": sample size and goodness of fit in structural equation models with latent variables. In: Child development, pp 134-146

64. Hayduk LA (1987) Structural equation modeling with LISREL: essentials and advances. Johns Hopkins University Press, Baltimore

65. Schumacker RE, Lomax RG (1996) A beginner's guide to structural equation modeling. Mahwah, New Jersey

66. Schubert T, Friedmann F, Regenbrecht H (1999) Embodied presence in virtual environments. In: Visual representations and interpretations, pp 268-278
67. Hair JF, Anderson RE, Tatham RL, Black WC (1998) Multivariate data analysis with readings. Prentice Hall International, Upper Saddle River

Marcel Heerink is a senior lecturer and researcher at the Information Engineering Institute of the Amsterdam University of Applied Sciences. He teaches HCI and research methodology and his research interests are in the fields of HRI and Technology Acceptance.

Ben Kröse is an associate professor at the University of Amsterdam, where he leads a group in Computational Intelligence and Autonomous Systems. As of 2004 he is part time lector at the Amsterdam University of Applied Science, where he leads a group in the field of Digital Life and Smart Homes.

Vanessa Evers is an assistant professor at the Human Computer Studies Lab at the University of Amsterdam. Her research focuses on cultural aspects of HCI and Human Interaction with Autonomous Agents such as robots or systems that learn. She is active in the HRI and CHI communities.

Bob Wielinga is a full professor of social science informatics at the University of Amsterdam. His research focus has been the methodology of knowledge-based system design and knowledge acquisition. Wielinga was and is team leader of several research projects, including KADS, ACKnowledge, REFLECT and KADS-II. 